\title{
2nd International Symposium for ICS \& SCADA Cyber Security Research 2014 (ICS-CSR 2014)
}

St Pölten, Austria

11-12 September 2014

Editors

Dr. Helge Janicke

Dr Kevin Jones 


\section{Abstract}

The 2nd International Symposium for Industrial Control System \& SCADA Cyber Security Research (ICSCSR 2014) brings together researchers with an interest in the security of industrial control systems in the light of their increasing exposure to cyber-space. ICS-CSR is a research conference aimed at high quality academic research in the cyber security of industrial control system from the hardware, system and human-factor perspectives.

\section{Sponsors}

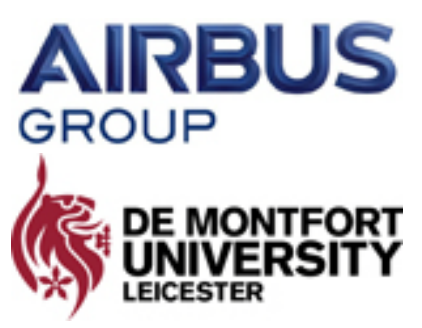




\section{Full Synopsis}

The 2nd International Symposium for Industrial Control System \& SCADA Cyber Security Research (ICSCSR 2014) brings together researchers with an interest in the security of industrial control systems in the light of their increasing exposure to cyber-space. ICS-CSR is a research conference aimed at high quality academic research in the cyber security of industrial control system from the hardware, system and human-factor perspectives.

We are very pleased to have a number of high quality research contributions this year that range from research experience in setting up test-beds for ICS research to descriptions of new attacks and defences against existing industrial control systems. The research reported this year in ICS-CSR is covering sociotechnical aspects of ICS security as well as technical subjects such as automated security analyses of industrial plants.

We would like to thank Kaspersky Lab for running the Kaspersky Industrial Protection Simulation as part of the ICS-CSR symposium, and Airbus Innovation Works and St. Pölten University of Applied Sciences for helping in the organisation of this event. A particular thank you to all the members of our programme committee for providing so timely and excellent reviews of the submissions, the local organisers at St. Pölten University of Applied Sciences and of course the dedicated authors for submitting their work to this event.

Helge Janicke and Kevin Jones 


\section{Editors}

This conference was edited by:

Dr. Helge Janicke is a Reader in Computer Science at De Montfort University, Leicester (UK). He is heading the Software Technology Research Laboratory and is leading research on Cyber Security. His research interests are in particular the Cyber Security of Industrial Control Systems, Access Control and Policy-based System Management. He is chairing the International Symposium on ICS and SCADA Cyber Security Research and has published widely in this area of research.

Dr Kevin Jones is the Research Team Lead for Airbus Group Innovations Cyber Operations. He is active in the cyber security research community and holds a number of patents within the domain. He has many years' experience in consultancy to aid organisations in achieving accreditation to ISO27001 Standard on Information Security Management and lecturing in cyber security. Kevin joined Airbus Group in 2011 where he has worked on risk assessments, security architectures, and cyber operations in ICS/SCADA systems and critical national infrastructure (CNI). He is a Member of BCS, IEEE and ISC2 and is accredited as a Certified Information Systems Security Professional (CISSP) and ISO27001 Lead Auditor. 


\section{Papers:}

Laurens Lemaire, Jorn Lapon, Bart De Decker \& Vincent Naessens $\quad$ A SysML Extension for Security Analysis of Industrial Control Systems http://dx.doi.org/10.14236/ewic/ICSCSR2014.1

Benjamin Green, Daniel Prince, Utz Roedig, Jerry Busby \& David Hutchison Socio-Technical Security Analysis of Industrial Control Systems (ICS) http://dx.doi.org/10.14236/ewic/lCSCSR2014.2

Robin Chapas, Ana Hristova, Thomas Locher \& Sebastian Obermeier Securing Industrial Control Systems through Autonomous Hardening http://dx.doi.org/10.14236/ewic/ICSCSR2014.3

Antonio Sánchez Aragó, Enrique Redondo Martínez \& Sandra Salán Clares SCADA Laboratory and Test-bed as a Service for Critical Infrastructure Protection http://dx.doi.org/10.14236/ewic/ICSCSR2014.4

Peter Maynard, Kieran McLaughlin \& Berthold Haberler Towards Understanding Man-in-the-middle Attacks on IEC 60870-5-104 SCADA Networks http://dx.doi.org/10.14236/ewic/ICSCSR2014.5

Manuel Cheminod, Luca Durante, Lucia Seno \& Adriano Valenzeno Automated Analysis of Access Policies in Industrial Plants $\quad$ http://dx.doi.org/10.14236/ewic/lCSCSR2014.6

Alessio Antonini, Federico Maggi \& Stefano Zanero A Practical Attack Against a KNX-based Building Automation System $\quad$ http://dx.doi.org/10.14236/ewic/lCSCSR2014.7

Andrew Nicholson, Helge Janicke \& Antonio Cau Position Paper: Safety and Security Monitoring in ICS/SCADA Systems http://dx.doi.org/10.14236/ewic/ICSCSR2014.8

Kieran McLaughlin, Sakir Sezer, Paul Smith, Zhendong Ma \& Florian Skopik $\quad$ PRECYSE: Cyberattack Detection and Response for Industrial Control Systems http://dx.doi.org/10.14236/ewic/ICSCSR2014.9

Antoine Lemay, Marina Krotofil, José M. Fernandez \& Scott Knight $\quad$ Not all SCADA is Equal: Impact of Control Models on ICS Threat Landscape $\quad$ http://dx.doi.org/10.14236/ewic/ICSCSR2014.10 